\title{
The Effects Of Unannounced Quizzes On Student Performance: Further Evidence
}

Felix U. Kamuche, (E-mail: fkamuche@morehouse.edu), Morehouse College

\begin{abstract}
This study explores the impact of unannounced quizzes on students' performance on Quantitative Analysis examinations by comparing course sections with unannounced quizzes to sections with announced quizzes. The difference in academic performance between students with unannounced quizzes and students with announced quizzes was examined in this study. Test scores for the first and second semesters were compared between the students with unannounced quizzes and students with announced quizzes. A significant difference was found in academic performance between the group with unannounced quizzes and group with announced quizzes. The group with unannounced quizzes showed better performance than the control group with announced quizzes. Therefore, this study demonstrates that an unannounced quiz is more effective than announced quiz in Quantitative Analysis Performance.
\end{abstract}

\section{INTRODUCTION}

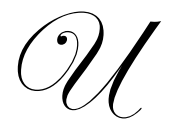

nannounced quizzes impact student performance and different subjects are better learned by the use of unannounced pop quizzes. Graham (1999) showed that average test scores for students who were exposed to unannounced quizzes were higher than those who were not exposed to unannounced quizzes. Bell (1997) used anonymous pop quizzes to measure student understanding, not simple memorization but to gauge effectiveness of course instruction. He showed that, the segments with anonymous pop quizzes achieved more gains. Kamuche (2005a) also established that test scores following weekly quizzes averaged half a letter grade higher than scores from sections without quizzes. There are no studies in the literature that directly compare announced with unannounced quizzes, and the indirect comparisons on hand seem to contradict one another (Graham, 1999). For example, Ballard and Johnson (2004) found an effect of pop quizzes on student performance, but Haberyan (2003) did not. Geist and Soehren (1997) and Solomon (1979) used announced quizzes, but only Geist and Soehren found an effect on student performance. For many parents, educators, researchers, and instructors, using unannounced quizzes and anonymous quizzes results in deeper levels of understanding and better long-term memory, than simply hearing, memorizing, or reading about a concept (Kamuche 2006, 2005a, 2005b; Bell 1997). This is what sets unannounced quizzes apart from other types of assessment tools routinely used in courses, such as tests, announced quizzes, and homework assignments. The purpose of this study is to explore the impact of unannounced quizzes on students' performance on Quantitative Analysis examinations by comparing course sections with unannounced quizzes to sections with announced quizzes. Unannounced quizzes in this study are synonymous with pop quizzes. To investigate this problem, the following literature review and the theoretical framework were used.

\section{LITERATURE REVIEW AND THE THEORETICAL FRAMEWORK FOR THE STUDY}

Developing and maintaining high quality instructional skills depend upon timely, effective feedback from students to instructors (Bell, 1997). This feedback is needed to assess student learning. There are several techniques that good instructors can use to improve the assessment and feedback process. For example, one method that is highly praised by Bonwell and Eison (1991), Felder (1992) and Mehta (1995) is active learning, in which students are expected to contribute actively during every class period (Bell, 1997). The author recently tried unannounced pop quiz, which is a slight different method, the author found to be simple and effective. The first day of class the author 
announce that quizzes would be unannounced. Thus, several times during the semester the author reserve the first few minutes of the period for a pop quiz. At the beginning reaction from the students was not favorable, but improves as the semester progresses.

One of the problems the author have experienced in teaching Basic Statistics and Quantitative Analysis courses is that many of his students seriously underestimate the difficulty of learning the material which results in low grades. The failure rate of this underestimation is troublesome especially at colleges where there is a concern about improving student learning (Graham, 1999). A number of poor test performances probably result from inadequate study time and/or poor arrangement of adequate study time (Graham, 1999). The author has frequently heard instructors express the belief that many students tend to cram just before tests rather than distributing their studying more evenly. To combat this perceived tendency to cram, the author employed unannounced pop quizzes prior to examinations. It is generally assumed that quizzes and tests are prerequisites for a successful completion of course works. In practice, college and university instructors list rules and guidelines related to quizzes and tests expectations for students. The author considers quizzes and tests to be student's responsibility and the student is expected to take all quizzes, tests, and complete all assignments. Faculty are expected to keep student quiz and tests records for evaluation and feedback process.

Numerous studies have investigated various aspects of the unannounced quizzes and student performance, which includes Anderson (1984), Beets and Lobingier (2001), Bell (1997), Bloom (1956), Dempster (1988), and Graham (1999), examined students' study behaviors and stress as well as their retention skills. More recently, Ferguson (2004), Kamuche (2005a), Koku, et al (2004), Krohn, et al (2005), Lawrence and Singhania (2004), and Mehta, (1995) studied students' perception of major functions of the unannounced quizzes. Findings of the above studies suggest both positive and negative aspects to the unannounced quiz alternative. On the positive side, unannounced quiz tends to reduce the rote memorization of facts, and so encourages students to study in more constructive ways (Anderson, 1984; Lawrence and Singhania, 2004; Mawhinney, et al 1971; Robins, et al 1995; Solomon, 1979). On the negative side the unannounced quizzes tends to increase the examination tension and stress, and did not offer a fair examination (Graham, 1999). Most education research has confirmed that frequent quizzes do yield benefits for example, Mawhinney, et al (1971) and Geist and Soehren (1997) compared test results of students who were exposed to pop quizzes with a control group who experience no quizzes. They found significantly higher scores for students who experienced pop quizzes and concluded that unannounced pop quizzing tends to enhance distribution of studying. The mean scores for these students were significantly higher than for students in the group who experienced no quizzes.

In one of the published studies of pop quizzing and student performance, Graham (1999) reported on a study of neuropsychology students and concluded that unannounced pop quizzing had a beneficial and significant influence on student performance. He further found that the positive effects on performance increased as unannounced quizzes increased (Freilich, 1989). Thus, he concluded that pop quizzes do matter for academic performance (Kamuche, 2005a). All including Kamuche, 2005a of these studies were conducted in science courses. McDougall and Granby (1996) also examined effects of pop quizzing on student performance in a behavioral science course. They found that pop quizzes were a determinant of student performance. These studies clearly suggest there is added value to students who take pop quizzes. If students who take pop quizzes outperform those who experienced no quizzes, it seems reasonable to conclude that something is occurring as a result of students who were exposed to unannounced pop quizzes. Therefore, the investigator hypothesized that students with unannounced quizzes, not only perform better on tests but also would learn more. This leads to the primary objective of this study. Null hypothesis for the study is that the group with unannounced quizzes would not have higher scores on an achievement test than the group with announced quizzes. Therefore, the operational hypothesis (alternate hypothesis) for this study is that the group with unannounced quizzes would have higher scores on an achievement test than the group with announced quizzes. 


\section{RESEARCH METHOD}

\section{Sample}

The sample in this study is made up of the students in the investigator's Quantitative Analysis classes for more than three academic years at Morehouse College. The typical enrollment in the classes was thirty-five students per class section with one or more sections being taught each semester. The total enrollments in the Quantitative Analysis courses each year ranged from 90 students in the first year to 105 students in the second and third years. The total enrollment in the Division of Economics and Business Administration at the college was approximately 1000 students. The total enrollment for the College was approximately 3000 students during the years of this study.

\section{Data Collection}

College policies required faculty, like in most colleges and universities to maintain complete and accurate students' attendance and tests records. These records served as the data sources for this study from 2000 to 2005 . The final year of data collection was the end of spring semester 2005. The sample size was 300 students.

\section{Procedures}

Students' enrollment records were maintained during the study years. To test student performance, the students in the course were given the same treatments (faculty, syllabus, texts, course preparation materials, and tests) for all years of the study. By using the same instructor for all sections, the author controlled the variations in instruction, lecture material, topic coverage, and students' abilities. Since multiple-choice method is an objective test in a quantitative subject such as Quantitative Analysis the possibility of grading bias is minimized. The academic records of 300 students who completed a Quantitative Analysis lecture course with announced and unannounced quizzes were examined, to compare their grades in Quantitative Analysis course. Test scores of students enrolled in both Quantitative Analysis classes were collected. Test scores for both of the first and second semesters were used. The test scores for each class were averaged to get a mean for each class. The experimental group $(\mathrm{N}=155)$ was sections with unannounced pop quizzes whereas the control group $(n=145)$ was sections with announced quizzes. Unannounced quizzes were given on any day of every week whereas announced quizzes were given on Thursdays and Fridays of every week. .

\section{RESULTS}

An independent $t$-Test was used to analyze the data with the $t$ score being $t=3.25$. The mean score for segment with unannounced quizzes was 78.2, while the mean score for segment with announced quizzes was 72.4. The standard deviation of the experimental group was 12.8 and the standard deviation for the control group was 16.4. At the .05 level of significance, the null hypothesis was rejected, indicating that students who were exposed to unannounced quizzes scored higher than the students who were exposed to announced quizzes. The author administered a 5-item Likert scale questionnaire at the end of the semester that asked the students to anonymously express their feelings about the quiz system (Graham, 1999). Based on the data collected from the segments with unannounced quizzes, $88 \%$ chose agree or strongly agree in answer to the question: 'In general, I think the use of unannounced quizzes is a good idea in this course," $83 \%$ chose agree or strongly agree in answer to the question: "The unannounced quizzes helped me to motivate myself to study more," and $70 \%$ chose agree or strongly agree in answer to the question: "I probably got better grades on the exams because of the pop quizzes".

\section{Discussion}

Based on the results of this study, segment with unannounced quizzes score better than segment with announced quizzes. This study provides evidence that faculty may possibly wish for unannounced quizzes for their students. Based on the results of the study, unannounced quizzes are quite relevant to student performance in Quantitative Analysis. Clearly, the author can say unannounced quizzes cause better performance. Further study is needed in different courses, especially in light of the findings for this study. The results of this study also suggest that 
unannounced quizzes are important for student learning. Further studies are needed to verify that the findings are consistent across disciplines.

\section{CONCLUSIONS}

The author feels that unannounced quizzes are an effective learning technique, and intends to use it again in the future courses where appropriate. The results of this study suggest that unannounced quizzes can be important to students' success. It is believed that unannounced quizzes encourage students to read the material prior to the lectures. The process also encourages students' attendance and improved student performance. There is no doubt that unannounced quizzes can deliver lasting benefits, especially for Quantitative Analysis students. It is likely that a majority of students in the experimental group value the use of unannounced quizzes in spite of any anxiety the process might cause them. They believe that the method should be used more often (Graham, 1999). Overall, this study has shown that unannounced quizzes were better than announced quizzes in improving students’ performance.

\section{ACKNOWLEDGMENTS}

Support for this research was provided by a summer research grant awarded to the author from the Division of Economics and Business Administration, Morehouse College.

\section{REFERENCES}

1. Anderson, J. E. (1984). Frequency of Quizzes in a Behavioral Science Course: An Attempt to Increase Medical Student Study Behavior. Teaching of Psychology, (11): 34-40.

2. Ballard, Charles L. and Johnson, Marianne F. (2004). Basic Math Skills and Performance in an Introductory Economics Class. Journal of Economic Education, vol. 35, no 1, (Winter): 3-24.

3. Beets, S. Douglas and Lobingier, Patricia, G., (2001). Pedagogical Techniques: Student Performance and Preferences. Journal of Education for Business vol. 76 no 4, (March/April): 231-235.

4. Bell, John T. (1997). Anonymous Quizzes: An Effective Feedback Mechanism. Chemical Engineering Education, vol. 31, no. 1, (Winter): 56-57.

5. Bloom, Benjamin S. (1956). Taxonomy of Educational Objectives: The Classification of Educational Goals, Handbook I: Cognitive Domain, David McKay Company, New York.

6. Bonwell, Charles C. and James, A. Eison (1991). Active Learning: Creating Excitement in the Classroom. ASHE-ERIC Higher Education Report No. 1, School of Education and Human Development, George Washington University.

7. $\quad$ Dempster, F. N. (1988). The Spacing Effect: A Case Study in the Failure to apply the Results of Psychological Research. American Psychologist, (43): 627-634.

8. $\quad$ Felder, Richard M. (1992). How About a Quick One? Chemical Engineering Education, vol. 26, (1): 22-30.

9. Ferguson, Sue, (2004). How Grades Fail Our Kids. Maclean's, vol. 117, no 2, (December): 28-35.

10. Freilich, Mark B., (1989). Frequent Quizzing, the Final Exam, and Learning: Is There a Correlation? Journal of Chemical Education vol. 66 no 3, (March): 219-223.

11. Geist, James, R. and Soehren, Stephen, E., (1997). The Effect of Frequent Quizzes on Short- and Long-Term Academic Performance. Journal of Dental Education vol. 61 no 4, (April): 339-345.

12. Graham, Robert, B., (1999). Unannounced Quizzes Raise Test Scores Selectively for Mid-Range Student. Teaching of Psychology vol. 26 no 4, (August): 271-273.

13. Haberyan, Kurt, A., (2003). Do Weekly Quizzes Improve Student Performance on General Biology Exams? American Biology Teacher vol. 65 no 2, (February): 110-114.

14. Kamuche, Felix U. (2006). Service Learning and Student Performance. Academic Exchange Quarterly, vol. 10, no. 3, (Fall): 187-192.

15. Kamuche, Felix U. (2005a). Do Weekly Quizzes Improve Student Performance? Academic Exchange Quarterly, vol. 9, no. 3, (December): 188-193.

16. Kamuche, Felix U. (2005b). Do Learning \& Teaching Styles Affect Student's Performance? An Empirical Study. Journal of Business and Economic, vol. 3, no.9, (September): 35-40. 
17. Koku, et al (2004). Overconfidence and the Performance of Business Students on Examinations. Journal of Education for Business, vol. 79, no 4, (March/April): 217-225.

18. Krohn, et al (2005). Student Effort and Performance over the Semester. Journal of Economic Education, vol. 36, no 1, (Winter): 3-29.

19. Lawrence, John, A. and Singhania, Ramp, P., (2004). A Study of Teaching and Testing Strategies for a Required Statistics Course for Undergraduate Business Students. Journal of Education for Business, vol. 79, no 6, (July/august): 333-339.

20. Mawhinney, V. T. et al (1971). A Comparison of Students' Studying Behavior produced by daily, weekly, and three-week testing schedules. Journal of Applied Behavior Analysis, (4): 257-264.

21. Mehta, Sudhir I. (1995). A Method for Instant Assessment and Active Learning. Journal of Engineering Education, vol. 84, no. 3, (July): 295-301.

22. McDougall, D. and Granby, C. (1996). How Expectation of Questioning Method Affects Undergraduates' Preparation for Class. Journal of Experimental Education, (65): 43-57.

23. Solomon, P. R. (1979). The Two-Point System: A Method for Encouraging Students to read assigned material before class. Teaching of Psychology, (6): 77-80.

24. Robins, Lynne S. et al (1995). The Effect of Pass/Fail Grading and Weekly Quizzes on First-Year Students' Performances and Satisfaction. Academic Medicine, vol. 70, no. 4, (April): 327-329.

\section{NOTES}


NOTES 